\title{
Prosthetic outcomes and clinical performance of CAD-CAM monolithic zirconia versus porcelain-fused-to-metal implant crowns in the molar region: 1-year results of a RCT
}

\author{
Mühlemann, Sven ; Lakha, Tabrez ; Jung, Ronald E ; Hämmerle, Christoph H F ; Benic, Goran I
}

\begin{abstract}
OBJECTIVE To investigate the clinical performance of monolithic zirconia implant crowns as compared to porcelain-fused-to-metal (PFM) implant crowns. MATERIALS AND METHODS Seventysix healthy patients received reduced diameter implants in the molar region. Following random allocation, either a monolithic zirconia crown $\left(\right.$ Mono- $\left.\mathrm{ZrO}_{2}\right)$ or a $(\mathrm{PFM})$ was inserted. Crown and implant survival rates, modified USPHS criteria, clinical measurements, and interproximal marginal bone level (MBL) were assessed at crown delivery (baseline, BL) and at the 1-year follow-up (1y-FU). Data were analyzed descriptively. Fisher's exact test and Wilcoxon rank sum test were applied for statistical analysis. The level of statistical significance was set at $\mathrm{p}<.05$. RESULTS Thirty-nine Mono- $\mathrm{ZrO}_{2}$ and $37 \mathrm{PFM}$ crowns were delivered. At the 1y-FU, one crown in each group was lost due to loss of the implant. Technical complications occurred in the PFM group and were limited to four minor ceramic chippings resulting in a total technical complication rate of $11.1 \%(\mathrm{p}=.024)$. Anatomical form and color match compared to the adjacent dentition were rated significantly inferior for the Mono- $\mathrm{ZrO}_{2}$ crowns. Patient satisfaction was high in both groups at $\mathrm{BL}\left(34 \mathrm{Mono}_{\mathrm{ZrO}} 34 \mathrm{PFM}\right)$ and at $1 \mathrm{y}-\mathrm{FU}$ (36 Mono- $\left.\mathrm{ZrO}_{2} 31 \mathrm{PFM}\right)$. No significant differences between the groups were detected with respect to the change in MBL and to the soft tissue parameters. CONCLUSIONS Monolithic zirconia crowns are a similarly successful alternative option to PFM crowns for restoring single implants in the posterior area.
\end{abstract}

DOI: https://doi.org/10.1111/clr.13631

Posted at the Zurich Open Repository and Archive, University of Zurich

ZORA URL: https://doi.org/10.5167/uzh-190177

Journal Article

Accepted Version

Originally published at:

Mühlemann, Sven; Lakha, Tabrez; Jung, Ronald E; Hämmerle, Christoph H F; Benic, Goran I (2020). Prosthetic outcomes and clinical performance of CAD-CAM monolithic zirconia versus porcelain-fusedto-metal implant crowns in the molar region: 1-year results of a RCT. Clinical Oral Implants Research, $31(9): 856-864$.

DOI: https://doi.org/10.1111/clr.13631 
DR. SVEN MÜHLEMANN (Orcid ID : 0000-0003-1253-1813)

DR. TABREZ LAKHA (Orcid ID : 0000-0002-8800-6153)

DR. RONALD ERNST JUNG (Orcid ID : 0000-0003-2055-1320)

PROF. CHRISTOPH H.F. HÄMMERLE (Orcid ID : 0000-0002-8280-7347)

DR. GORAN I. BENIC (Orcid ID : 0000-0001-7551-7934)

Article type : Original Research

\section{Prosthetic outcomes and clinical performance of CAD-CAM monolithic} zirconia versus porcelain-fused-to-metal implant crowns in the molar region: 1year results of a RCT

Sven Mühlemann', Tabrez Lakha ${ }^{1,2}$, Ronald E. Jung1, Christoph HF Hämmerle ${ }^{1}$, Goran I Benic $^{1}$

\section{Author's affiliations:}

1) Clinic of Reconstructive Dentistry, Center of Dental Medicine, University of Zurich, Zurich, Switzerland

2) M.A. Rangoonwala College of Dental Sciences \& Research Centre, Department of Prosthetic Dentistry, Pune, Maharashtra, India

\section{Running title:}

Clinical study on CAD-CAM monolithic zirconia implant crowns

\section{Corresponding author:}

This article has been accepted for publication and undergone full peer review but has not been through the copyediting, typesetting, pagination and proofreading process, which may lead to differences between this version and the Version of Record. Please cite this article as doi: 10.1111/CLR.13631

This article is protected by copyright. All rights reserved 
Sven Mühlemann

Clinic of Reconstructive Dentistry, Center of Dental Medicine, University of Zurich, Zurich, Switzerland Telephone number: +41446340404

sven.muehlemann@zzm.uzh.ch

\section{Key words:}

implant crowns, monolithic zirconia, titanium base, prosthetic outcomes

\section{Author contributions:}

S.M., R.J, C.H., G.B. conceived the ideas; S.M. und G.B. collected the data; S.M. and L.T. analysed the data; and S.M., L.T. and G.B. performed the writing

\section{Conflict of interest and source of funding statement}

S.M., R.J, C.H., G.B. provided lectures or consultations, which were reimbursed from Institut Straumann AG. S.M. provided lectures or consultations, which were reimbursed from 3M.

The authors report no financial interests related to any products involved in this study. This study was supported by an unrestricted grant from ITI Foundation and by the Clinic of Reconstructive Dentistry, Center of Dental Medicine, University of Zurich, Switzerland. Study materials such as implants and abutments were provided by Institut Straumann AG.

This article is protected by copyright. All rights reserved 


\section{ABSTRACT}

Objective: To investigate the clinical performance of monolithic zirconia implant crowns as compared to porcelain-fused-to-metal (PFM) implant crowns.

Materials and methods: Seventy-six healthy patients received reduced diameter implants in the molar region. Following random allocation, either a monolithic zirconia crown $\left(\mathrm{Mono}-\mathrm{ZrO}_{2}\right)$ or a (PFM) was inserted. Crown and implant survival rates, modified USPHS criteria, clinical measurements and interproximal marginal bone level (MBL) were assessed at crown delivery (baseline, BL) and at the 1-year follow-up (1y-FU). Data was analyzed descriptively. Fisher's exact test and Wilcoxon rank sum test were applied for statistical analysis. The level of statistical significance was set at $\mathrm{p}<0.05$.

Results: 39 Mono- $\mathrm{ZrO}_{2}$ and 37 PFM crowns were delivered. At the 1y-FU, one crown in each group was lost due to loss of the implant. Technical complications occurred in the PFM group and were limited to 4 minor ceramic chippings resulting in a total technical complication rate of $11.1 \%(p=0.024)$. Anatomical form and color match compared to the adjacent dentition were rated significantly inferior for the Mono- $\mathrm{ZrO}_{2}$ crowns. Patient satisfaction was high in both groups at $\mathrm{BL}$ (34 Mono- $\mathrm{ZrO}_{2} / 34 \mathrm{PFM}$ ) and at 1y-FU (36 Mono- $\mathrm{ZrO}_{2} / 31 \mathrm{PFM}$ ). No significant differences between the groups were detected with respect to the change in MBL and to the soft tissue parameters.

Conclusions: Monolithic zirconia crowns are a similarly successful alternative option to PFM crowns for restoring single implants in the posterior area. 


\section{1 / INTRODUCTION}

Different restoration materials are available for the fabrication of implant-supported single crowns. Porcelain-fused-to-metal (PFM) implant crowns are considered the gold standard presenting an estimated 5-year survival rate of $98.3 \%$ (Pjetursson, et al., 2018). In systematic reviews, however, fracture of the ceramic veneering is reported as the most frequent technical complication with a 5-year complication rate of $16.7 \%$ (Pjetursson, Asgeirsson, Zwahlen \& Sailer, 2014).

The use of ceramic materials for the fabrication of implant crowns is a possible treatment option. Systematic reviews reported high survival rates for all-ceramic implant crowns of $95.8 \%$ after 5 years and 94.4\% after 10 years (Jung, Zembic, Pjetursson, Zwahlen \& Thoma, 2012; Rabel, Spies, Pieralli, Vach \& Kohal, 2018). However, implant-supported all-ceramic crowns exhibit a relatively high rate of technical complications. The most frequent type of technical complications was chipping with a complication rate of $9 \%$ after 5 years (Rabel, et al., 2018). Furthermore, significantly more porcelain-fused-to-zirconia implant crowns failed due to the fractures of veneering ceramic as compared to PFM crowns (Pjetursson, et al., 2018).

Advances in material science enabled to increase the translucency of conventional yttriastabilized zirconia (Zhang, 2014; Zhang, Lee, Srikanth \& Lawn, 2013). The use of so-called translucent zirconia, however, is limited to the posterior area because of the lower translucency as compared to traditional glass-ceramics (Zhang, Reveron, Spies, Van Meerbeek \& Chevalier, 2019). Monolithic ceramic reconstructions allow to avoid the technique sensitive manual veneering process and may therefore result in better clinical outcomes in comparison to veneered reconstructions.

To date, only two clinical studies evaluating the use of monolithic zirconia for single implant crowns have been. A clinical study with a 1-year follow-up found 22 screw-retained monolithic zirconia crowns to be free of ceramic chippings, whereas two chippings were detected in 22 cemented PFM crowns (Weigl, et al., 2019). Another clinical study reported no technical complications of 18 monolithic zirconia implant crowns after an observation period between 12 and 36 months (Worni, Katsoulis, Kolgeci, Worni \& Mericske-Stern, 2017).

Monolithic zirconia is processed by means of computer-aided design and computer-aided manufacturing (CAD-CAM). A systematic review showed that time efficiency for the laboratory fabrication was improved by the use of CAD-CAM technology (Mühlemann, Kraus, Hämmerle \& 
Thoma, 2018b). In countries, in which manual technical manufacturing is more expensive than industrial fabrication, CAD-CAM reconstructions additionally offer a cost-effective option to PFM reconstructions. Still, CAD-CAM reconstructions need to fulfill the same criteria of clinical quality as conventional reconstructions. A clinical study evaluating tooth-supported crowns fabricated with different CAD-CAM systems and the conventional fabrication method found no differences in the final quality of the reconstruction (Mühlemann, Benic, Fehmer, Hämmerle \& Sailer, 2018a).

The primary aim of the present randomized controlled trial was to test whether CAD-CAM monolithic zirconia implant crowns show less technical complications as compared to PFM implant crowns in the molar region. The study hypothesis was that CAD-CAM monolithic zirconia implant crowns present a lower technical complication rate.

This article is protected by copyright. All rights reserved 


\section{2 / MATERIALS AND METHODS}

\section{1 / Study design}

The study was designed as a prospective randomized controlled clinical trial with 2 parallel study groups. The clinical protocol was approved by the local ethical committee (PB_2016-01977) and registered at ClinicalTrials.gov (NCT02272491). All patients provided informed consent prior participation. The study was conducted at the Clinic of Reconstructive Dentistry, University of Zurich, Switzerland. This article is reported following CONSORT (Moher, et al., 2010).

\section{2 / Study population}

Seventy-six partially edentulous patients in need of a single implant-supported crown in at least one maxillary or mandibular molar site were recruited. The subjects had to fulfill the following inclusion criteria:

- 18-80 years of age

- In need of a single implant crown in the maxillary or mandibular molar region

- Implant position allowing a screw-retention of the crown

- Presence of an antagonist

The reasons for exclusion were:

- Women pregnant at the date of inclusion

- Known or suspected non-compliance, drug or alcohol abuse

- $\quad$ Full-mouth plaque score (FMPS) $>30 \%$

- Smoking of more than 15 cigarettes per day

- Temporomandibular disorders

\section{2 / Implant placement}

The implant surgery was timed as a type 2, type 3, or type 4 procedure (Hämmerle, Araujo, Simion \& Osteology Consensus, 2012). All surgeries were performed according to the clinic's standard protocol (Benic, et al., 2013) and following the implant manufacturer's instructions for the placement of the implants. All sites received titanium-zirconium narrow-diameter implants (Straumann ${ }^{\circledR}$ Standard Plus SLActive RN, Roxolid, $3.3 \mathrm{~mm}$ diameter, Institut Straumann AG, 
Basel Switzerland). All implants were left for transmucosal healing.

\section{3 / Randomization}

Three to six months after implant placement, the implant impression was taken. At this time point, patients were randomly allocated to one of the treatment modalities according to a computer-generated randomization list. Allocation to the study groups was concealed by a person not involved in the study using an electronic data capture software (secuTrial, Clinical Trials Center, University Hospital Zurich) at the time of final impression taking. One of the following randomly assigned implant crowns was fabricated:

- Test group: monolithic $3 \mathrm{~mol} \%$ yttria partially stabilized zirconia zirconia crown (Lava Plus, 3M, Seefeld, Germany) bonded to a titanium base abutment (Straumann ${ }^{\circledR}$ RN Variobase with $1 \mathrm{~mm}$ mucosal height, Institut Straumann AG)

- Control group: PFM crown consisting of a gold abutment (Straumann ${ }^{\circledR}$ RN synOcta cast gold abutment, Institut Straumann AG) with castable high nobel gold alloy (VClassic, Cendres Métaux, Biel, Switzerland) and feldspathic veneering ceramic (Creation CC Willi Geller, Klema, Meiningen, Germany)

\section{4 / Prosthetic procedures}

An intraoral scanner (iTero, Align Technology Inc, San José, USA) was used to take an impression of the quadrant with the implant and the scan body (Straumann ${ }^{\circledR}$ Scan Body RN, Institut Straumann AG), of the opposing quadrant, and of the bite in maximal intercuspation. In case of additionalprosthetic treatments that were not related to the study, it was allowed to take a full-arch open-tray (screw-retained impression post RN, Institut Straumann AG) impression using polyether material (Permadyne, 3M). Alginate was used for the impression of the opposing jaw and silicone (Preciform N HardBite, Merz Dental, Lütjenburg, Germany) was applied for the bite registration.

All crowns were fabricated by one experienced master dental technician (Andreas Graf, Atelier für Zahntechnik, Zürich). In the test group, Mono- $\mathrm{ZrO}_{2}$ crowns were fabricated using a laboratory-based CAD (Straumann ${ }^{\circledR}$ CARES Visual 10.4.0, Institut Straumann AG) and an industrial CAM process (Straumann ${ }^{\circledR}$ etkon, Institut Straumann AG). In case of a conventional 
impression, models were poured in dental stone (SheraPure, SHERA, Lemförde, Germany). After at least 24 hours, a laboratory scanner (Straumann ${ }^{\circledR}$ CARES Scan CS2) was used for model scanning and further processing in the same CAD-CAM workflow.

In the control group, either the milled digital model or the conventional model was used for the fabrication of the PFM crown. The conventional manufacturing included the lost-wax technique for the casting of the high noble gold core followed by manual layering of the veneering ceramic followed by ceramic firing (Austromat M, DEKEMA, Freilassing, Germany) according to the manufacturers' instructions.

At a try-in appointment, all implant crowns were evaluated and if needed chairside adjustments were performed. Thereafter, the laboratory finalization of the Mono- $\mathrm{ZrO}_{2}$ crowns included polishing and staining procedures (CreaColor, Creation Willi Geller). The submucosal part of the crown was left unstained to keep a highly polished zirconia surface in contact with the peri-implant mucosa. The titanium base abutment was abraded applying air-borne particles of 50 $\mu \mathrm{m}$ aluminium oxide (Rocatec, $3 \mathrm{M}$ ) from a distance of $1 \mathrm{~cm}$ for 15 seconds using 2.8 bar blast pressure The abutment and the crown were cleaned with ethanol and the bonding surfaces were treated with a primer (Espe Sil, 3M). Subsequently the crown was luted onto the abutment using a chemically curing composite cement (Multilink Hybrid Abutment, Ivoclar Vivadent, Schaan). The laboratory finalization in the PFM crowns included veneering, glazing, and polishing procedures.

Each implant crown was screw-retained with the implant specific torque of $35 \mathrm{Ncm}$. The screw access hole was filled with Teflon tape and sealed with a composite filling (Filtek, 3M).

\section{5 / Clinical examination and outcome measures}

All patients were recalled for the baseline examination 1-2 weeks after crown insertion (BL) and 1 year later (1y-FU). For standardization purposes, two calibrated operators performed all clinical examinations. Operators were calibrated by a meeting and by conjointly conducting clinical examinations in pilot patients before the study. Technical and biological outcomes, and adverse events (according to ISO 14155: 3.2) were assessed at BL and at 1y-FU. Clinical pictures of the implant crown and the neighboring dentition were taken at each visit.

\section{Technical outcomes}


Prosthetic parameters were evaluated using modified USPHS (United States Public Health Service) criteria (Table 1). In brief, patient satisfaction was determined. The reconstructions were examined for fractures of the veneering ceramic and the abutment. Marginal adaptation between crown and abutment was evaluated with a dental probe (Aesculap DA470R, Tuttlingen, Germany). Interproximal contact points were checked with dental floss. Occlusion and articulation were checked using a double folded occlusion foil (HANEL Shimstock foil $8 \mu \mathrm{m}$, Langenau, Germany). The match of the anatomical form as well as of the color of the crown to the neighboring dentition were compared visually. The occlusal wear was examined visually and by using the dental probe to check for exposed rough surfaces.

All implant crowns were checked for further technical complications: abutment screw loosening, fracture of the abutment screw, fracture of the implant, and loss of the occlusal composite filling. Specifically, the Mono- $\mathrm{ZrO}_{2}$ crowns were controlled whether debonding of the crown from the abutment was detectable.

The total technical complication rate on the prosthetic level (primary outcome) included fracture of the veneering ceramic, fracture of the crown, fracture of the abutment, fracture of the abutment screw, loosening of the abutment screw, loss of the occlusal filling, and decementation.

\section{Biological outcomes}

Periodontal parameters were assessed at six sites around each study implant and the mesial and distal dentition. These included probing pocket depth (PPD), bleeding on probing score (BOP; (Ainamo \& Bay, 1976)), plaque control record (PCR; (O'Leary, Drake \& Naylor, 1972)). The width of the keratinized mucosa (KM) was assessed at the mid buccal aspect of the study implant and the teeth mesially and distally.

\section{MBL}

Standardized periapical digital radiographs (Digora Optime, Soredex, Helsinki, Finland) were taken at $\mathrm{BL}$ and at the $1 \mathrm{y}-\mathrm{FU}$ by means of the paralleling technique using a rim holder directing the X-ray beam perpendicular to the implant axis. The radiographs were imported in an open-source image software (Image J; National Institutes of Health, Bethesda, Maryland). A calibrated and independent investigator evaluated the radiographs. The distance between the 
implant shoulder and the first bone to implant contact was measured at the mesial and distal aspect of each implant to the nearest $0.1 \mathrm{~mm}$. The implant length and the pitch distance between two implant threads served as reference for the calibration of each radiograph. MBL changes were calculated from BL to FU-1Y. A loss of marginal bone is described as a negative change in MBL.

Statistical Analysis:

The primary outcome was the total technical complication rate after 5 years. A systematic review calculated an annual rate of the total number of technical complications of $6.33 \%$, translating into a 5-year complication rate of $27.1 \%$ (Pjetursson, et al., 2014). The most frequent technical complication was ceramic chipping with an annual complication rate of $3.65 \%$ and a 5 year complication rate of $16.7 \%$. It was hypothesized that a clinically relevant decrease of the 5year total complication rate by $80 \%$ may be achieved using a monolithic zirconia crown. This assumption was used for the following size calculation. In order to determine sample size a onesided two-sample comparison of proportions power calculation was used (statistical software $\mathrm{R}$ 3.0.2). A sample size of 35 in each group would have $80 \%$ power to detect a difference in the complication rate between control group (27.1\%) and test group (5.4\%) assuming that the test group showed a significantly (0.05 significance level) lower complication rate. When a patient drop-out rate of $10 \%$ is assumed, the target sample size in each group increased to 38 . The present study is an interim analysis of the primary outcome in this randomized controlled clinical trial.

For the statistical analysis, the values around each implant and neighboring tooth for PCR, BOP, and PPD were averaged to one value each. For the MBL the mesial and distal values were analyzed separately. Discrete values were described with absolute frequencies and tested for differences in proportions using Fisher's exact test. For continuous parameters, the data were reported by means, standard deviations, ranges, medians, and interquartile ranges and the Wilcoxon rank sum test was applied for statistical analysis. Results of tests with p-values $\leq 0.05$ were considered statistically significant. All statistical analyses and plots were computed with the statistical software R (R Core Team, 2018) including the package tidyverse (Hadley Wickham, 2017).

This article is protected by copyright. All rights reserved 


\section{3 / RESULTS}

In total 76 patients were included in this study from January 2015 to February 2018. Of these, 39 patients (mean age 57.7 years; 17 females and 22 males) were in the $\mathrm{Mono}^{-\mathrm{ZOO}_{2}}$ group and 37 patients (mean age 56.4 years; 17 females and 20 males) in the PFM group. In one patient randomized to the PFM group erroneously a Mono- $\mathrm{ZrO}_{2}$ crown was delivered. The incorrect randomization was detected at BL. Consensus was achieved among the investigators to keep the subject in the study. The frequency distribution of study implants according to tooth position and treatment group is presented in Table 2. In 16 Mono- $\mathrm{ZrO}_{2}$ crowns and 18 PFM crowns an optical scanner was used for the impression, whereas in 23 Mono- $\mathrm{ZrO}_{2}$ crowns and 19 PFM crowns a conventional impression was taken.

At 1 year, 74 of the 76 patients attended the follow-up examination. No adverse events were recorded. One crown in each treatment group was lost due to loss of the implant. In the Mono- $\mathrm{ZrO}_{2}$ group one implant fractured after 11 months, whereas in the PFM group one implant was lost without any signs of inflammation after 3 months. These failures yielded an implant/crown survival rate of $97.4 \%$ and $97.3 \%$, respectively.

\section{1 / Technical outcomes}

At the $1 \mathrm{y}-\mathrm{FU}$, in 4 PFM crowns a fracture of the veneering ceramic was detected $(11.1 \%)$ (Figure 1), whereas none of the Mono- $\mathrm{ZrO}_{2}$ crowns showed a ceramic fracture. All fractures in the PFM crowns were polishable. No further technical complications were observed. The difference in the total technical complication rate between the treatment groups was statistically significant $(p=0.024)$.

The modified USPHS criteria at BL and at 1y-FU are presented in Table 3. Patient satisfaction was high in both groups with no significant difference between treatment groups at BL $(p=0.7)$ and at the $1 \mathrm{y}-\mathrm{FU}(p=0.26)$. In the Mono- $\mathrm{ZrO}_{2}$ group the anatomical form and the color match as compared to the neighboring dentition were significantly better rated for PFM crowns $(p=0.005$ and $p=0.0035)$ (Figure 2).

After one year, in 3 Mono- $\mathrm{ZrO}_{2}$ crown the mesial contact point was lost, whereas in one PFM crown the distal contact point was lost. In the same time period the occlusal contact was lost in 4 Mono- $\mathrm{ZrO}_{2}$ crowns and in 6 PFM crowns. After 1 year of clinical service, significantly more 
occlusal wear was detected in the PFM crowns as compared to the Mono- $\mathrm{ZrO}_{2}$ crowns $(p=0.02)$.

\section{2 / Biological outcomes}

The results of PCR, BOP, PPD and KM are presented in Table 4. No statistically significant difference was calculated for PCR and BOP between the Mono- $\mathrm{ZrO}_{2}$ group and the PFM group at $\mathrm{BL}(p=1 ; p=0.33)$ nor at $1 \mathrm{y}-\mathrm{FU}(p=0.81 ; p=0.90)$. The mean change of PPD after one year was not statistically different between treatment groups for the implant site $(p=0.98)$.

\section{$3.3 / \mathrm{MBL}$}

From BL to the $1 \mathrm{y}-\mathrm{FU}$ the median change of mesial and distal MBL amounted to -0.07 $\mathrm{mm}($ mean \pm SD: $-0.15 \pm 0.76 \mathrm{~mm}$ ) and $-0.29 \mathrm{~mm}($ mean \pm SD: $-0.19 \pm 0.90 \mathrm{~mm})$ in the Mono$\mathrm{ZrO}_{2}$ group and to $-0.42 \mathrm{~mm}($ mean $\pm \mathrm{SD}:-0.33 \pm 0.71 \mathrm{~mm}$ ) and $-0.16 \mathrm{~mm}$ (mean $\pm \mathrm{SD}:-0.22 \pm$ $0.66 \mathrm{~mm}$ ) in the PFM group. There were no statistically significant differences between the Mono$\mathrm{ZrO}_{2}$ group and the PFM group (mesial: $p=0.1153$; distal: $p=0.9586$ ). In each treatment group one implant showed more than $2 \mathrm{~mm}$ of bone loss at the mesial aspect. In the Mono- $\mathrm{ZrO}_{2}$ group the same implant was affected at the distal aspect. 


\section{4 / DISCUSSION}

The 1-year results of the present randomized controlled clinical study showed that monolithic zirconia implant crowns in the molar region were free of technical complications, whereas for PFM implant crowns the total 1-year technical complication rate amounted to $11.1 \%$. Therefore, the study hypothesis could be accepted.

Patient satisfaction was high in both treatment groups irrespective of significantly lower ratings in color and form match for monolithic zirconia implant crowns. In each treatment group one crown was lost due to implant failure. There were no differences between the monolithic zirconia implant crowns and the PFM implant crowns regarding soft tissue parameters and the changes of the MBL.

These findings are in agreement with the data reported in previous clinical studies investigating monolithic zirconia implant-supported crowns (Weigl, et al., 2019; Worni, et al., 2017). In these studies no ceramic fractures were detected and a $100 \%$ reconstruction survival was reported. In the present study the crown survival rate, however, was lower due to the loss of two implants. In the Mono- $\mathrm{ZrO}_{2}$ group, one reduced diameter implant fractured. The second implant was lost in the PFM group after the patient experienced a painful chewing event in the region of the implant. Thereafter, the implant became continuously mobile and could be manually removed under local anesthesia. No signs of marginal bone loss or peri-implant infection were noted prior to the loss of osseointegration. In a 5-year randomized controlled study investigating $6 \mathrm{~mm}$-long soft tissue-level implants, the failures of short implants presented similar characteristics as in the present trial. It was hypothesized that the loss of implant osseointegration was induced by a short but intense biomechanical overload during chewing. Even though titanium-zirconium narrow diameter implants showed high survival rates in clinical studies (Iegami, et al., 2017) (Ioannidis, et al., 2015)(Lambert, et al., 2015), the use of this type of implant negatively affected the crown survival rate and might represent a limitation of the present study in the case of further future implant failures.

Nevertheless, the results of the present study are promising since the use of monolithic zirconia implant crowns has the potential to reduce the rate of technical complication rate for single implant crowns. In systematic reviews evaluating the clinical performance of single implant crowns the fracture of the veneering ceramic was reported as the most frequent technical complication (Pjetursson, et al., 2014; Pjetursson, et al., 2018). The amount of chipping of the 
veneering ceramic was similar between veneered all-ceramic implant crowns and PFM implant crowns (Pjetursson, et al., 2018). The failure rate of all-ceramic crowns due to material fractures, however, was significantly higher as compared to conventional PFM crowns (Pjetursson, et al., 2018). The results of the present study confirmed the risk for ceramic fractures for PFM crowns, whereas monolithic zirconia crowns were free of ceramic fractures. Therefore, monolithic zirconia has the potential to reduce the total complication rate and consequently, the failure rate of allceramic implant crowns. In addition, chairside time during follow-up examinations may be reduced as chipped ceramic surfaces need polishing procedures in order to minimize the risk for further ceramic fractures (Sax, Hämmerle \& Sailer, 2011).

Zirconia restorations inevitably involve CAD-CAM technology. A systematic review showed that the time efficiency for the laboratory fabrication of single implant crowns in the posterior area was increased (Mühlemann, et al., 2018b). Therefore, monolithic zirconia implant crowns may be an economical alternative in countries, where industrial processes are cheaper than manual work the dental technicians' provided that the criteria of clinical quality are fulfilled.

The color match and the anatomical form of the Mono- $\mathrm{ZrO}_{2}$ implant crowns, however, were rated significantly worse as compared to conventionally fabricated PFM implant crowns. A major deviation in color match was reported for $15 \%$ of the monolithic zirconia implant crowns. A clinical study using the same scale for the evaluation of clinical quality demonstrated that the color deviation was outside the normal range in $3 \%$ of the monolithic zirconia restorations (Worni, et al., 2017). The lower rating of color match for monolithic zirconia crowns in the present study may be attributed to the industrial CAM process that does not allow the individual coloring of the zirconia prior to sintering. Similarly, the anatomical form was rated ideal in $60 \%$ of the monolithic zirconia crowns as compared to $89 \%$ of the PFM crowns, which was a significant difference $(p=0.005)$.

The results of the present study may be related to the devices and settings of the CADCAM workflow used for the fabrication of monolithic zirconia crowns (Tapie, et al., 2015). A recent study reported that the clinical quality of monolithic CAD-CAM depends on the specific digital workflow used for the fabrication (Mühlemann, et al., 2018a). Another clinical study showed that the rescan of a CAD-CAM acrylic prototype that was manually adapted in a try-in session resulted in an ideal anatomical form in up to $97 \%$ of the final zirconia restorations (Worni, et al., 2017). Independently of the lower ratings for color match and anatomical form of 
monolithic zirconia implant crowns, patient satisfaction was as high as in the patients that received a PFM crown. However, the ratings for color and anatomical form highly depend on the examiner and this may therefore be a limitation of the present study.

The clinical results of the present study showed that the use of monolithic zirconia for implant crowns in the posterior area eliminated the risk for ceramic fractures and consequently positively influenced the total technical complication rate after 1 year. Still, long-term investigations are needed reporting the survival and success rates of monolithic zirconia implant crowns. Patients should be informed that CAD-CAM implant crowns made out of monolithic zirconia may not fulfill high esthetic expectations. Therefore, the clinical indication of monolithic zirconia is restricted to non-esthetic sites such as molars.

\section{CONCLUSIONS}

The short-term results of the present randomized controlled clinical trial suggest that monolithic zirconia crowns are a valuable alternative to PFM crowns for restoring single implants in the molar region. 


\section{5 / LEGENDS}

Table 1 Modified USPHS criteria used to evaluate the single implant crowns

Table 2 Distribution of implant crowns according to tooth position; Mono- $\mathrm{ZrO}_{2}$, monolithic zirconia; PFM, porcelain fused to metal

Table 3 Prosthetic outcomes based on the modified USPHS criteria; Mono- $\mathrm{ZrO}_{2}$, monolithic zirconia implant crowns; PFM, porcelain fused to metal implant crowns

Table 4 Results of the clinical parameters at BL and at 1y-FU; BOP, bleeding on probing; $\mathrm{IQR}$, interquartile range; KM, width of keratinized mucosa; $\mathrm{n}$, number; PCR, plaque control record; PPD, probing pocket depth; $\mathrm{SD}$, standard deviation; Mono- $\mathrm{ZrO}_{2}$, monolithic zirconia; PFM, porcelain fused to metal

Figure 1 Fractures of the ceramic veneering in 4 porcelain-fused-to-metal crowns.

Figure 2 Representative implant crowns showing the rating for the color match; alpha, no deviation in color and translucency between crown and neighboring dentition; bravo, slight deviation in color and translucency between crown and neighboring dentition; charlie, major deviation in color and translucency between crown and neighboring dentition; $\mathrm{Mono}-\mathrm{ZrO}_{2}$, monolithic zirconia; PFM, porcelain-fused-to-metal 


\section{6 / REFERENCES}

Ainamo, J. \& Bay, I. (1976). [Periodontal indexes for and in practice]. Tandlaegebladet, 80, 149-152.

Benic, G. I., Gallucci, G. O., Mokti, M., Hämmerle, C. H., Weber, H. P. \& Jung, R. E. (2013). Titaniumzirconium narrow-diameter versus titanium regular-diameter implants for anterior and premolar single crowns: 1-year results of a randomized controlled clinical study. Journal of Clinical Periodontology, 40, 1052-1061. doi:10.1111/jcpe.12156

Hadley Wickham (2017) Tidyverse. $\mathrm{R}$ package version 1.2.1: https://CRAN.Rproject.org/package=tidyverse.

Hämmerle, C. H., Araujo, M. G., Simion, M. \& Osteology Consensus, G. (2012). Evidence-based knowledge on the biology and treatment of extraction sockets. Clinical Oral Implants Research, 23 Suppl 5, 80-82. doi:10.1111/j.1600-0501.2011.02370.x

legami, C. M., Uehara, P. N., Sesma, N., Pannuti, C. M., Tortamano Neto, P. \& Mukai, M. K. (2017). Survival rate of titanium-zirconium narrow diameter dental implants versus commercially pure titanium narrow diameter dental implants: A systematic review. Clinical Implant Dentistry and Related Research, 19, 1015-1022. doi:10.1111/cid.12527

loannidis, A., Gallucci, G. O., Jung, R. E., Borzangy, S., Hämmerle, C. H. \& Benic, G. I. (2015). Titaniumzirconium narrow-diameter versus titanium regular-diameter implants for anterior and premolar single crowns: 3-year results of a randomized controlled clinical study. Journal of Clinical Periodontology, 42, 1060-1070. doi:10.1111/jcpe.12468

Jung, R. E., Zembic, A., Pjetursson, B. E., Zwahlen, M. \& Thoma, D. S. (2012). Systematic review of the survival rate and the incidence of biological, technical, and aesthetic complications of single crowns on implants reported in longitudinal studies with a mean follow-up of 5 years. Clinical Oral Implants Research, 23 Suppl 6, 2-21. doi:10.1111/j.1600-0501.2012.02547.x

Lambert, F. E., Lecloux, G., Grenade, C., Bouhy, A., Lamy, M. \& Rompen, E. H. (2015). Less Invasive Surgical Procedures Using Narrow-Diameter Implants: A Prospective Study in 20 Consecutive Patients. Journal of Oral Implantology, 41, 693-699. doi:10.1563/aaid-joi-d-13-00201

Moher, D., Hopewell, S., Schulz, K. F., Montori, V., Gotzsche, P. C., Devereaux, P. J., Elbourne, D., Egger, M., Altman, D. G. \& Consolidated Standards of Reporting Trials, G. (2010). CONSORT 2010 Explanation and Elaboration: Updated guidelines for reporting parallel group randomised trials. Journal of Clinical Epidemiology, 63, e1-37. doi:10.1016/j.jclinepi.2010.03.004

Mühlemann, S., Benic, G. I., Fehmer, V., Hämmerle, C. H. F. \& Sailer, I. (2018a). Clinical quality and efficiency of monolithic glass ceramic crowns in the posterior area: digital compared with conventional workflows. Int J Comput Dent, 21, 215-223.

Mühlemann, S., Kraus, R. D., Hämmerle, C. H. F. \& Thoma, D. S. (2018b). Is the use of digital technologies for the fabrication of implant-supported reconstructions more efficient and/or more effective

This article is protected by copyright. All rights reserved 
than conventional techniques: A systematic review. Clin Oral Implants Res, 29 Suppl 18, 184-195. doi:10.1111/clr.13300

O'Leary, T. J., Drake, R. B. \& Naylor, J. E. (1972). The plaque control record. Journal of Periodontology, 43, 38. doi:10.1902/jop.1972.43.1.38

Pjetursson, B. E., Asgeirsson, A. G., Zwahlen, M. \& Sailer, I. (2014). Improvements in implant dentistry over the last decade: comparison of survival and complication rates in older and newer publications. International Journal of Oral and Maxillofacial Implants, 29 Suppl, 308-324. doi:10.11607/jomi.2014suppl.g5.2

Pjetursson, B. E., Valente, N. A., Strasding, M., Zwahlen, M., Liu, S. \& Sailer, I. (2018). A systematic review of the survival and complication rates of zirconia-ceramic and metal-ceramic single crowns. Clinical Oral Implants Research, 29 Suppl 16, 199-214. doi:10.1111/clr.13306

R Core Team (2018) R: A language and environment for statistical computing. R Foundation for Statistical Computing, Vienna, Austria. URL https://www.R-project.org/.

Rabel, K., Spies, B. C., Pieralli, S., Vach, K. \& Kohal, R. J. (2018). The clinical performance of all-ceramic implant-supported single crowns: A systematic review and meta-analysis. Clinical Oral Implants Research, 29 Suppl 18, 196-223. doi:10.1111/clr.13337

Sax, C., Hämmerle, C. H. \& Sailer, I. (2011). 10-year clinical outcomes of fixed dental prostheses with zirconia frameworks. International journal of computerized dentistry, 14, 183-202.

Tapie, L., Lebon, N., Mawussi, B., Fron-Chabouis, H., Duret, F. \& Attal, J. P. (2015). Understanding dental $\mathrm{CAD} / \mathrm{CAM}$ for restorations--accuracy from a mechanical engineering viewpoint. International journal of computerized dentistry, 18, 343-367.

Weigl, P., Saarepera, K., Hinrikus, K., Wu, Y., Trimpou, G. \& Lorenz, J. (2019). Screw-retained monolithic zirconia vs. cemented porcelain-fused-to-metal implant crowns: a prospective randomized clinical trial in split-mouth design. Clinical Oral Investigations, 23, 1067-1075. doi:10.1007/s00784-018-2531-x

Worni, A., Katsoulis, J., Kolgeci, L., Worni, M. \& Mericske-Stern, R. (2017). Monolithic zirconia reconstructions supported by teeth and implants: 1- to 3-year results of a case series. Quintessence International, 48, 459-467. doi:10.3290/j.qi.a38138

Zhang, F., Reveron, H., Spies, B. C., Van Meerbeek, B. \& Chevalier, J. (2019). Trade-off between fracture resistance and translucency of zirconia and lithium-disilicate glass ceramics for monolithic restorations. Acta biomaterialia, 91, 24-34. doi:10.1016/j.actbio.2019.04.043

Zhang, Y. (2014). Making yttria-stabilized tetragonal zirconia translucent. Dental Materials, 30, 1195-1203. doi:10.1016/j.dental.2014.08.375

Zhang, Y., Lee, J. J., Srikanth, R. \& Lawn, B. R. (2013). Edge chipping and flexural resistance of monolithic ceramics. Dental Materials, 29, 1201-1208. doi:10.1016/j.dental.2013.09.004

This article is protected by copyright. All rights reserved 
Table 1

\begin{tabular}{|c|c|c|}
\hline Parameters & Rating & Criteria \\
\hline \multirow{4}{*}{ Patient satisfaction } & Alpha & Very satisfied. No complaints. \\
\hline & Bravo & $\begin{array}{l}\text { Critics regarding aesthetics, chewing, or comfort. Short term } \\
\text { complaints after treatment. }\end{array}$ \\
\hline & Charlie & Unsatisfied. Constant complaints but tolerable. \\
\hline & Delta & Completely unsatisfied. Unbearable complaints. \\
\hline \multirow{4}{*}{ Ceramic fracture } & Alpha & No fracture. \\
\hline & Bravo & Chipping (localized), but polishing/contouring possible. \\
\hline & Charlie & Chipping down to the framework. \\
\hline & Delta & New crown is needed. \\
\hline \multirow{4}{*}{ Abutment fracture } & Alpha & No fracture \\
\hline & Bravo & - \\
\hline & Charlie & - \\
\hline & Delta & Fracture of abutment. New crown is neede. \\
\hline \multirow{4}{*}{ Marginal fit } & Alpha & Perfect fit. No gap that could be probed. \\
\hline & Bravo & Slight under- over-contour. Probe catch but no gap. \\
\hline & Charlie & Clear gap. Gap that could be probed. \\
\hline & Delta & New crown is needed. \\
\hline \multirow{4}{*}{ Anatomical form } & Alpha & $\begin{array}{l}\text { Ideal anatomical form. Contour is continuous with the } \\
\text { neighbouring dentition. }\end{array}$ \\
\hline & Bravo & $\begin{array}{l}\text { Slightly over- or under-contoured as compared to the } \\
\text { neighbouring dentition. }\end{array}$ \\
\hline & Charlie & $\begin{array}{l}\text { Severely over- or under-contoured as compared to the } \\
\text { neighbouring dentition. }\end{array}$ \\
\hline & Delta & New crown is needed. \\
\hline \multirow{4}{*}{$\begin{array}{l}\text { Proximal contact } \\
(\text { mesial/distal) }\end{array}$} & Alpha & Tight proximal contact point. \\
\hline & Bravo & Weak proximal contact point. \\
\hline & Charlie & Open proximal contact point. \\
\hline & Delta & - \\
\hline \multirow{2}{*}{ Occlusal contact } & Alpha & $\begin{array}{l}\text { Occlusal contacts on the crown and the neighbouring dentition } \\
\text { equal in strength. }\end{array}$ \\
\hline & Bravo & $\begin{array}{l}\text { Increased occlusal contacts on the crown. No occlusal contacts } \\
\text { on neighbouring dentition. }\end{array}$ \\
\hline
\end{tabular}

This article is protected by copyright. All rights reserved 


\begin{tabular}{|c|c|c|}
\hline & Charlie & $\begin{array}{l}\text { No occlusal contact on the crown. Normal occlusal contacts on } \\
\text { neighbouring dentition. }\end{array}$ \\
\hline & Delta & - \\
\hline \multirow{4}{*}{ Color match } & Alpha & $\begin{array}{l}\text { No deviation in color and translucency between crown and } \\
\text { neighbouring dentition. }\end{array}$ \\
\hline & Bravo & $\begin{array}{l}\text { Slight deviation in color and translucency between crown and } \\
\text { dentition. Deviation lies within natural range of dentition. }\end{array}$ \\
\hline & Charlie & $\begin{array}{l}\text { Major deviation in color and translucency between crown and } \\
\text { dentition. Deviation lies outside natural range of dentition. }\end{array}$ \\
\hline & Delta & - \\
\hline \multirow{3}{*}{ Occlusal wear } & Alpha & No occlusal wear. \\
\hline & Bravo & Slight occlusal wear, diameter of spot $<2 \mathrm{~mm}$. \\
\hline & Charlie & High occlusal wear, diameter of spot $>2 \mathrm{~mm}$. \\
\hline
\end{tabular}


Table 2

\begin{tabular}{|l|c|c|c|c|c|c|c|c|}
\hline implant site & 16 & 17 & 26 & 27 & 36 & 37 & 46 & 47 \\
\hline $\begin{array}{l}\text { Mono Zr02 } \\
(\mathrm{n}=39)\end{array}$ & 5 & 1 & 2 & 1 & 14 & 1 & 11 & 4 \\
\hline PFM (n=37) & 1 & 0 & 6 & 1 & 17 & 0 & 10 & 2 \\
\hline
\end{tabular}


Table 3

\begin{tabular}{|c|c|c|c|c|c|}
\hline \multirow{2}{*}{ Parameter } & & \multicolumn{2}{|c|}{ Baseline } & \multicolumn{2}{|c|}{1 year Follow up } \\
\hline & & Mono ZrO2 & PFM & Mono ZrO2 & PFM \\
\hline \multirow{5}{*}{ Patient satisfaction } & $\mathbf{n}$ & 39 & 37 & 38 & 36 \\
\hline & A & 34 & 34 & 36 & 31 \\
\hline & B & 5 & 3 & 2 & 5 \\
\hline & C & 0 & 0 & 0 & 0 \\
\hline & D & 0 & 0 & 0 & 0 \\
\hline \multirow{5}{*}{ Ceramic fracture } & $\mathbf{n}$ & 39 & 37 & 38 & 36 \\
\hline & A & 39 & 37 & 38 & 32 \\
\hline & B & 0 & 0 & 0 & 4 \\
\hline & C & 0 & 0 & 0 & 0 \\
\hline & D & 0 & 0 & 0 & 0 \\
\hline \multirow{5}{*}{ Abutment fracture } & $\mathbf{n}$ & 39 & 37 & 38 & 36 \\
\hline & A & 39 & 37 & 38 & 36 \\
\hline & B & - & - & - & - \\
\hline & C & - & - & - & - \\
\hline & D & 0 & 0 & 0 & 0 \\
\hline \multirow{5}{*}{ Marginal fit } & $\mathbf{n}$ & 39 & 37 & 38 & 36 \\
\hline & A & 34 & 37 & 34 & 36 \\
\hline & B & 5 & 0 & 4 & 0 \\
\hline & C & 0 & 0 & 0 & 0 \\
\hline & D & 0 & 0 & 0 & 0 \\
\hline \multirow{5}{*}{ Anatomical form } & $\mathbf{n}$ & 39 & 37 & 38 & 36 \\
\hline & A & 24 & 33 & 23 & 32 \\
\hline & B & 14 & 4 & 14 & 4 \\
\hline & C & 1 & 0 & 1 & 0 \\
\hline & D & 0 & 0 & 0 & 0 \\
\hline \multirow{3}{*}{ Proximal contact mesial } & $\mathbf{n}$ & 39 & 37 & 38 & 36 \\
\hline & A & 35 & 33 & 31 & 28 \\
\hline & B & 4 & 4 & 4 & 8 \\
\hline
\end{tabular}




\begin{tabular}{|c|c|c|c|c|c|}
\hline & C & 0 & 0 & 3 & 0 \\
\hline & D & - & - & - & - \\
\hline \multirow{5}{*}{ Proximal contact distal } & $\mathbf{n}$ & 26 & 21 & 25 & 21 \\
\hline & A & 24 & 20 & 21 & 18 \\
\hline & B & 2 & 1 & 4 & 2 \\
\hline & C & 0 & 0 & 0 & 1 \\
\hline & D & - & - & - & - \\
\hline \multirow[t]{2}{*}{ 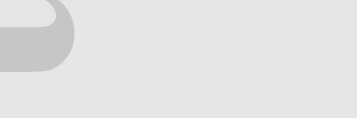 } & $\mathrm{n}$ & 39 & 37 & 38 & 36 \\
\hline & A & 31 & 31 & 26 & 24 \\
\hline \multirow[t]{3}{*}{ Occlusal contact } & B & 0 & 0 & 0 & 0 \\
\hline & C & 8 & 6 & 12 & 12 \\
\hline & D & - & - & - & - \\
\hline \multirow{5}{*}{ Color match } & $\mathbf{n}$ & 39 & 37 & 38 & 36 \\
\hline & A & 10 & 19 & 7 & 16 \\
\hline & B & 23 & 18 & 24 & 20 \\
\hline & C & 6 & 0 & 7 & 0 \\
\hline & D & - & - & - & - \\
\hline \multirow{5}{*}{ Occlusal wear } & $\mathbf{n}$ & 39 & 37 & 38 & 36 \\
\hline & A & 39 & 37 & 24 & 13 \\
\hline & B & 0 & 0 & 14 & 23 \\
\hline & C & 0 & 0 & 0 & 0 \\
\hline & & & & & \\
\hline
\end{tabular}


Table 4

\begin{tabular}{|c|c|c|c|c|c|c|c|c|}
\hline & & & \multicolumn{3}{|c|}{ Mono ZrO2 crown } & \multicolumn{3}{|c|}{ PFM crown } \\
\hline & & & mesial site & implant site & distal site & mesial site & implant site & distal site \\
\hline \multirow{5}{*}{ 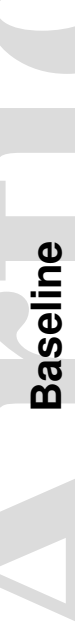 } & & & $\mathrm{n}=39$ & $\mathrm{n}=39$ & $\mathrm{n}=26$ & $\mathrm{n}=37$ & $\mathrm{n}=37$ & $\mathrm{n}=21$ \\
\hline & PCR \% & $\begin{array}{l}\text { Mean } \pm \text { SD } \\
\text { Range }\end{array}$ & $\begin{array}{l}10.3 \pm 15.3 \\
0-66.7\end{array}$ & $\begin{array}{l}3.9 \pm 9.2 \\
0-33.3\end{array}$ & $\begin{array}{l}27.6 \pm 21.0 \\
0-66.7\end{array}$ & $\begin{array}{l}12.2 \pm 19.1 \\
0-83.3\end{array}$ & $\begin{array}{l}3.6 \pm 8.9 \\
0-33.3\end{array}$ & $\begin{array}{l}21.4 \pm 23.1 \\
0-83.3\end{array}$ \\
\hline & BOP \% & $\begin{array}{l}\text { Mean } \pm \text { SD } \\
\text { Range }\end{array}$ & $\begin{array}{l}7.3 \pm 11.4 \\
0-33.3\end{array}$ & $\begin{array}{l}14.5 \pm 18.1 \\
0-50.0\end{array}$ & $\begin{array}{l}12.2 \pm 14.0 \\
0-50.0\end{array}$ & $\begin{array}{l}9.5 \pm 12.1 \\
0-33.3\end{array}$ & $\begin{array}{l}10.8 \pm 16.3 \\
16.7-66.7\end{array}$ & $\begin{array}{l}13.5 \pm 15.5 \\
0-50.0\end{array}$ \\
\hline & PPD mm & $\begin{array}{l}\text { Mean } \pm \text { SD } \\
\text { Range }\end{array}$ & $\begin{array}{l}2.3 \pm 0.4 \\
1.5-3.5\end{array}$ & $\begin{array}{l}3.0 \pm 0.5 \\
2-4\end{array}$ & $\begin{array}{l}2.6 \pm 0.5 \\
2-3.3\end{array}$ & $\begin{array}{l}2.4 \pm 0.5 \\
1.7 \pm 3.8\end{array}$ & $\begin{array}{l}3.0 \pm 0.6 \\
1.8-4.5\end{array}$ & $\begin{array}{l}2.8 \pm 0.3 \\
1.8-3.5\end{array}$ \\
\hline & $\mathrm{KM} \mathrm{mm}$ & $\begin{array}{l}\text { Mean } \pm \text { SD } \\
\text { Range }\end{array}$ & $\begin{array}{l}3.3 \pm 1.4 \\
0-7\end{array}$ & $\begin{array}{l}2.4 \pm 1.1 \\
1-5\end{array}$ & $\begin{array}{l}3.0 \pm 1.3 \\
0-5\end{array}$ & $\begin{array}{l}2.8 \pm 1.4 \\
0-6\end{array}$ & $\begin{array}{l}2.6 \pm 1.3 \\
1-6\end{array}$ & $\begin{array}{l}2.8 \pm 1.2 \\
1-5\end{array}$ \\
\hline \multirow{4}{*}{ 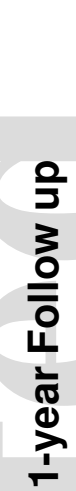 } & & & $\mathrm{n}=38$ & $\mathrm{n}=38$ & $n=26$ & $\mathrm{n}=36$ & $\mathrm{n}=36$ & $\mathrm{n}=20$ \\
\hline & PCR \% & $\begin{array}{l}\text { Mean } \pm \text { SD } \\
\text { Range }\end{array}$ & $\begin{array}{l}17.5 \pm 23.9 \\
33.3-100\end{array}$ & $\begin{array}{l}5.2 \pm 10.1 \\
0-33.3\end{array}$ & $\begin{array}{l}24.0 \pm 21.1 \\
0-83.3\end{array}$ & $\begin{array}{l}19.0 \pm 28.5 \\
0-100\end{array}$ & $\begin{array}{l}5.6 \pm 14.4 \\
0-66.6\end{array}$ & $\begin{array}{l}27.0 \pm 23.8 \\
0-66.7\end{array}$ \\
\hline & BOP \% & $\begin{array}{l}\text { Mean } \pm \text { SD } \\
\text { Range }\end{array}$ & $\begin{array}{l}9.2 \pm 15.0 \\
0-50.0\end{array}$ & $\begin{array}{l}19.3 \pm 23.0 \\
0-83.4\end{array}$ & $\begin{array}{l}16.7 \pm 18.4 \\
0-66.7\end{array}$ & $\begin{array}{l}12.5 \pm 19.2 \\
16.7-83.3\end{array}$ & $\begin{array}{l}15.7 \pm 16.9 \\
33.3-66.7\end{array}$ & $\begin{array}{l}14.3 \pm 21.2 \\
0-66.7\end{array}$ \\
\hline & PPD mm & $\begin{array}{l}\text { Mean } \pm \text { SD } \\
\text { Range }\end{array}$ & $\begin{array}{l}2.3 \pm 0.4 \\
1.7-3.5\end{array}$ & $\begin{array}{l}3.1 \pm 0.5 \\
2-4.7\end{array}$ & $\begin{array}{l}2.6 \pm 0.4 \\
2-3.5\end{array}$ & $\begin{array}{l}2.3 \pm 0.5 \\
1.5-3.8\end{array}$ & $\begin{array}{l}3.1 \pm 0.6 \\
2-5.7\end{array}$ & $\begin{array}{l}2.8 \pm 0.4 \\
2-3.5\end{array}$ \\
\hline & $\mathrm{KM} \mathrm{mm}$ & Mean \pm SD & $3.4 \pm 1.2$ & $2.3 \pm 1.1$ & $2.6 \pm 1.3$ & $3.5 \pm 1.2$ & $2.6 \pm 1.2$ & $2.7 \pm 1.1$ \\
\hline
\end{tabular}




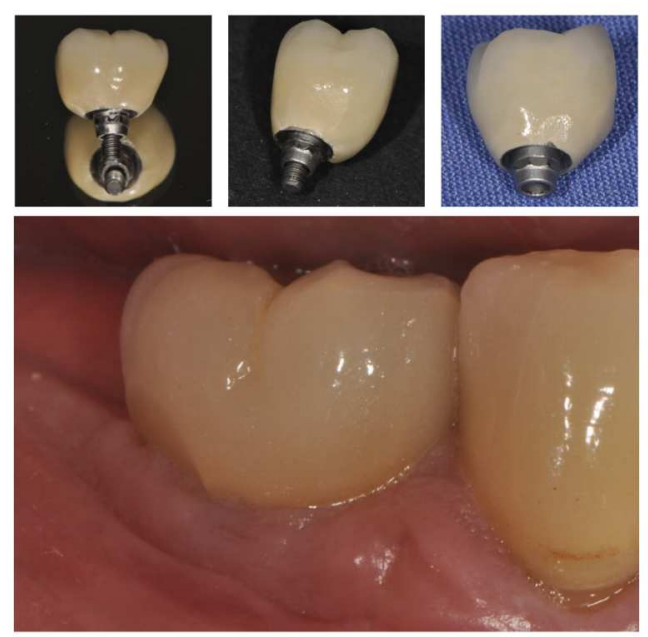

clr_13631_f1.tiff 


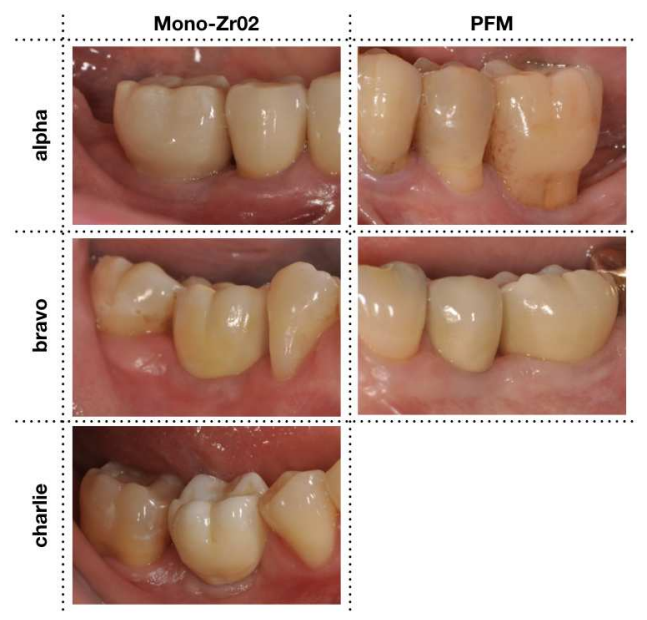

clr_13631_f2.tiff 